This is a peer-reviewed, accepted author manuscript of the following research chapter: Mbongwe, B., Moinami, J., Masupe, T., Tapera, R., Molefe, T., Erick, P., ... Massele, A. (Accepted/In press). Nature and sources of poisoning in patients admitted to a referral hospital in Gaborone, Botswana: findings and implications. Hospital Practice.

\title{
Nature and sources of poisoning in patients admitted to a referral hospital in Gaborone, Botswana; findings and implications
}

Bontle Mbongwe, $\mathrm{PhD}^{1}$, Jacqueline Moinami, BSc${ }^{1}$, Tiny Masupe, MBBch², Roy Tapera, MPH${ }^{1}$, Tshenkego Molefe, $\mathrm{BSc}^{1}$, Patience Erick, $\mathrm{PhD}^{1}$, Brian Godman, $\mathrm{PhD}^{3,4,5,6^{*}}$, Amos Massele, PhD, $\mathrm{MD}^{7}$

1Department of Environmental Health, Faculty of Health Sciences, University of Botswana, Gaborone, Botswana. Email: mbongwe@UB.AC.BW; jaymoinami@gmail.com; Taperar@UB.AC.BW; popsymolf@gmail.com; erickp@UB.AC.BW

${ }^{2}$ Department of Family Medicine \& Public Health, Faculty of Medicine, University of Botswana, Gaborone, Botswana. Email: Masupet@UB.AC.BW

${ }^{3}$ Department of Laboratory Medicine, Division of Clinical Pharmacology, Karolinska Institutet, Karolinska University Hospital Huddinge, Stockholm, Sweden: Email: Brian.Godman@ki.se ${ }^{4}$ Strathclyde Institute of Pharmacy and Biomedical Sciences, University of Strathclyde, Glasgow, United Kingdom. Email: Brian.godman@strath.ac.uk

${ }^{5}$ Division of Public Health Pharmacy and Management, School of Pharmacy, Sefako Makgatho Health Sciences University, Ga-Rankuwa, Pretoria, South Africa

${ }^{6}$ Health Economics Centre, Liverpool University Management School, Chatham Street, Liverpool, UK. Email: Brian.Godman@liverpool.ac.uk

${ }^{7}$ Department of Biomedical Sciences, Faculty of Medicine, University of Botswana, Gaborone,

Botswana. Email: masselea@mopipi.ub.bw

*Corresponding Author: Strathclyde Institute of Pharmacy and Biomedical Sciences, University of Strathclyde, Glasgow G4 ORE, United Kingdom. Email: Brian.godman@strath.ac.uk. Telephone: +44 141548 3825. Fax: +44 1415522562 and Division of Clinical Pharmacology, Karolinska Institute, Karolinska University Hospital Huddinge, SE-141 86, Stockholm, Sweden. Email: Brian.Godman@ki.se. Telephone + 468 58581068. Fax + 46859581070

(Accepted for publication Hospital Practice)

\begin{abstract}
Background: Intentional poisoning is becoming an important public health concern particularly among young women globally. Consequently, there is a need to analyse this further within countries to establish pertinent policies to reduce current incidence rates. This includes sub-Saharan African countries where there has been a scarcity of information. Consequently, we sought to establish the nature and sources of poisoning in patients admitted to a leading hospital in Botswana to help develop pertinent future policies for Botswana and surrounding countries. Methods: Retrospectively reviewing the medical records of all patients admitted to Princess Marina Hospital (PMH), which is a leading tertiary hospital in the capital city of Botswana, due to acute poisoning over a six-year period. Results: The records for 408 patients were reviewed. The majority of admissions (58\%) were females, and the mean age of patients was 21( \pm 14$)$ years. Most poisoning cases $(53 \%)$ were intentional. The 15-45 years age group was most likely to intentionally poison themselves compared to other age groups, with females four and half times more likely to intentionally poison themselves compared to males (AOR 4.53, 95\% Cl: 2.68- 7.89, $p<0.001$ ). Half of the patients were poisoned by medicines followed by household chemicals $(22 \%)$, with females overall four times more likely to be poisoned by medicines compared to males. The medicine mostly ingested was paracetamol $(30 \%)$. Failing relationships $(57 \%)$ were the principal reason for intentional poisoning. Six patients died from poisoning representing a $1.5 \%$ mortality rate. Conclusions: The findings suggest in-depth and urgent investigations on intentional poisoning are needed among young women across countries including sub-Saharan African countries to inform future policies on prevention strategies. Further, strategies for poisoning prevention should target social and family relationship problems. We will be following this up in the future.
\end{abstract}

\section{Introduction}

Acute poisoning is a major life-threatening problem globally, with the annual incidence estimated at between 0.2 and 0.9 poison exposures per 1000 population and rising (1). Total admissions for acute poisoning in some African countries including South Africa is estimated at $17 \%$ of total ward admissions in children $(2,3)$. Globally, the World Health Organization (WHO) estimates approximately 
346,000 deaths annually are due to poisoning, with deaths due to unintentional poisoning now exceeding 100,000 a year $(4,5) .90 \%$ of these deaths occur in lower and middle-income countries (LMICs), enhanced by typically insufficient regulations for drugs and chemicals as well as easier access to toxic chemicals (6-8). Despite these concerns, poisoning remains an under-recognized burden partly due to many poisonings and exposures occurring in countries and regions that lack medical toxicologists and poison control centers (9).

Poisoning can occur as a result of a wide range of substances including household chemicals (10), medicines such as paracetamol (11-13), pesticides $(12,14,15)$, and injections of poisonous chemicals through insect stings or animal bites (16-18). Traditionally, acute poisoning is reported more among males than females $(17,19)$. However, a few studies have reported an increasing trend among women (20-22), with attempted suicides now higher in younger women including students than men (21-23). Women of reproductive age are now the most vulnerable regarding intentional poisoning and committing suicide through medicines such as paracetamol $(20$, 24-26). A study conducted among students in Iran admitted to hospital found appreciably more women than men were admitted (200 out of 248 admissions) (23), and a recent study in Botswana showed more women are now presenting with intentional toxic ingestion than men (27). This raises serious concerns in a country already burdened by maternal mortality, HIV, TB, rising noncommunicable diseases (NCDs) and substance abuse (28).

The public health challenge is that whilst mortality from acute poisoning is generally low, it is usually high in victims of suicide $(29,30)$. This is a concern especially among females in their reproductive age, which could increase poverty levels when single mothers die leaving children without an income. In Botswana, $64.4 \%$ of women who died between 2012 and 2014 were single mothers, most of whom left orphaned children in poverty (31). If not prioritized, poisoning could be an additional burden to increasing maternal mortality, challenging Botswana's target of reducing deaths and illnesses from hazardous chemicals and other substances by 2030 in line with the Sustainable Development Goals (SDGs) (32), particularly SDG 3 whose focus is on ensuring healthy lives and promoting wellbeing for all. There will be similar issues in other sub-Saharan African countries.

While studies investigating poisoning in Botswana are limited, it is worth noting that out of the few investigations undertaken, deaths from acute poisoning ranged from $0.7-2.6 \%$ of admitted patients $(27,33-35)$. The agents responsible for the fatalities include traditional and other medicines, paraffin, household chemicals and pesticides $(27,33,35,36)$. Additionally, there is evidence of an increasing number of admissions to Accident and Emergency (A \& E) Departments in Botswana due to acute poisoning, rising from $1.9 \%$ in 2010 (34) to 2.7 in 2017 (27).

These observations call for further investigations to inform the development of pertinent interventions to prevent acute poisoning in Botswana. Consequently, we sought to assess recent trends, types, and sources of acute poisoning in patients admitted to a leading hospital in Botswana with specific attention to gender, age, factors influencing intentional poisoning and substances used.

Subsequently, we will use the findings to suggest potential future strategies to the authorities in Botswana to help achieve SDG 3 targets. We hope our findings will be of interest to other subSaharan African countries facing similar challenges with high rates of both infectious and noninfectious diseases and concerns with rising poisoning rates.

\section{Materials and Methods}

\subsection{Study Design and setting:}

This was a cross-sectional analytical study based on a retrospective review of medical records of patients admitted to Princess Marina Referral Hospital (PMH) for acute poisoning between January 2012 and December 2018. Additional clarification was sought from hospital staff where pertinent and feasible.

The city of Gaborone has a population of 231,592 , which constitutes $11 \%$ of the total population in Botswana (37). PMH is one of the two public referral hospitals in Botswana and was chosen for the study as it is the largest and oldest public tertiary referral hospital in Botswana, and where patients with acute poisoning are likely to be admitted due to low user fees. It currently has an estimated capacity of 567 beds. 
Data collected from the medical records of patients included their age, gender, marital and socioeconomic status, sources and types of poisoning.

\subsection{Study population and sample size:}

Cases of acute poisoning were identified by reviewing the admission records of all out-patients presenting at the A\&E Department from 2012 to 2018. The records reviewed included in-patient and out-patient registers, patient case files and death registers. Hospital staff provided additional information where pertinent and feasible.

In order to find the outcomes of acute poisoning, the records of patients who were admitted from A\&E were followed up in the different wards to which they were admitted as in-patients. These wards were female, male medical, intensive care unit, female surgical, male surgical and paediatrics.

Triangulation using different types of records was performed to enhance data quality.

Our inclusion criteria were both children and adult patients received at the A \& E Department because of either intentional (self -poisoning) or unintentional (accidental) poisoning from alcohol, illicit drugs, agrochemicals, medicines, venomous creatures and household chemicals. Patients admitted due to food poisoning or who used other methods of deliberate self-harm such as hanging or laceration only, or cases of adverse reaction to medicines, were excluded.

The age groups of patients were typically broken down into deciles with infants, children and teenagers further broken down into 0 to 4 years, 5 to 12 years and 13 to 19 years respectively. The age groups were further consolidated into infants and children ( $0-14$ years), childbearing age (15-45 years) and non-childbearing age (46 years and above) for additional analysis.

\subsection{Data Collection:}

A pre-tested checklist was used to collect data from the hospital medical records. The data included demographic characteristics, nature of poisoning, sources of poisoning, routes of exposure and poisoning outcomes. This was developed based on the findings of previous studies $(20,25,27,33$, 38).

The nature of any poisoning was subsequently categorised into intentional and unintentional poisoning. The phrase "intentional poisoning" will be used interchangeably with suicide or self harm where appropriate. The phrase unintentional poisoning will be used interchangeably with accidental poisoning.

\subsection{Data analysis:}

Data was transferred to Statistical Package for Social Sciences (SPSS) version 25 for analysis. Descriptive statistics were used to compute means and standard deviations for numerical variables. Chi square statistics were used to test significance of associations between various factors likely to influence acute poisoning. Chi Square was also used to compare the types and sources of acute poisoning among the different age groups and to match outcomes of the acute poisoning with demographic characteristics.

\subsection{Ethics:}

Permission to conduct the study was granted by the University of Botswana Institutional Review Board, the Ministry of Health and Wellness ethics committee and the PMH ethics review committee.

\section{Results}

\subsection{Description of study participants}

Hospital records from 408 patients were retrieved. The mean age of patients was $21.2( \pm 14)$ years (SD) with a range of 0.6 months to 85 years. The majority of patients $(41 \%)$ were in the $20-30$-year age group, female (58\%) and from urban areas. Out of the 408 records $236(57.8 \%)$ were admitted. One hundred and seventy-six (43\%) of admissions were self-referrals and $60(15 \%)$ were referrals from a local clinic or hospital (Table 1). 
Table 1: Distribution of patients by age, gender and location of poisoning

\begin{tabular}{lll}
\hline Characteristic & Frequency & Proportion (\%) \\
\hline Age: & $\mathbf{n = 4 0 8}$ & \\
$0-4$ & 81 & 19.9 \\
$5-12$ & 22 & 5.4 \\
$13-19$ & 56 & 13.7 \\
$20-30$ & 168 & 41.2 \\
$31-40$ & 50 & 12.3 \\
$41-50$ & 20 & 4.9 \\
$51-60$ & 4 & 1.0 \\
$>60$ & 6 & 1.5 \\
Unspecified age & 1 & 0.2 \\
Gender: & & \\
Male & 172 & 42.2 \\
Female & 235 & 57.6 \\
Unspecified gender & 1 & 0.2 \\
Location: & & \\
Urban & 203 & 49.8 \\
Rural & 174 & 42.6 \\
Unspecified & 31 & 7.6 \\
\hline
\end{tabular}

\subsection{Nature of poisoning by gender and age}

More than half of all poisoning cases were intentional (53\%), $44 \%$ accidental and $3 \%$ could not be classified. Intentional poisoning was higher in females $(76 \%)$, with accidental poisoning more common in males $(61 \%)$. Accidental poisoning cases were only recorded for the age groups $0-4$ years and $51-$ 60 years. Of all the accidental poisoning cases recorded, $43 \%$ were in children under 5 . On the other hand, of all the intentional poisoning cases, the age group 20 to 30 years $(62 \%)$ had the highest number of cases.

Further grouping of age groups into infants and children (0-14 years), reproductive age group (15-45 years), and the non-reproductive age group (46 years and above), showed that $70 \%$ of patients in the reproductive age-group intentionally poisoned themselves. Overall, the 15-45 years age group was nine times more likely to intentionally poison themselves compared to appreciably lower rates in the other two age groups (AOR 9.3, 95\% Cl: 1.38-62.6), with females four and half times more likely to intentionally poison themselves compared to males (AOR 4.53, 95\% Cl: 2.68- 7.89, p < 0.001(Table 2).

Table 2: Associations with age, gender and nature of poisoning ( $N=408)$

\begin{tabular}{lccc}
\hline Independent & & \multicolumn{2}{c}{ Adjusted } \\
\cline { 3 - 4 } $\begin{array}{l}\text { Variables } \\
\text { Age group (years) }\end{array}$ & Number (\%) & OR & $\mathbf{9 5 \% C l}$ \\
$\quad 0-14$ & $108(26.5)$ & 0.29 & $0,047-1.87$ \\
$\quad 15-45$ & $285(69.9)$ & 9.3 & $1.38-62.6$ \\
$\quad 16$ and above & $14(3.4)$ & $1 \dagger$ & - \\
& & & \\
Gender & $172(42.3)$ & $1^{\dagger}$ & - \\
$\quad$ Male & $235(57.7)$ & 4.53 & $2.68-7.89$
\end{tabular}

NB: OR = Odd ratio, $\mathrm{Cl}=$ confidence interval, ${ }^{\dagger}$ reference group 


\subsection{Sources of poisoning:}

The top five sources of acute poisoning were medicines (49\%), household chemicals (22\%), venomous creatures (9\%), wild mushrooms and other plants $(6 \%)$ and agrochemicals $(5 \%)$.

\subsection{Sources of poisoning by gender and age}

Medicines contributed the highest number of poisoning cases for both females and males; however, females were poisoned more by medicines than males $(75 \%)$. Poisoning by sources other than medicines was highest among males (Figure 1).

\section{Figure 1 - Source of poisoning and gender}

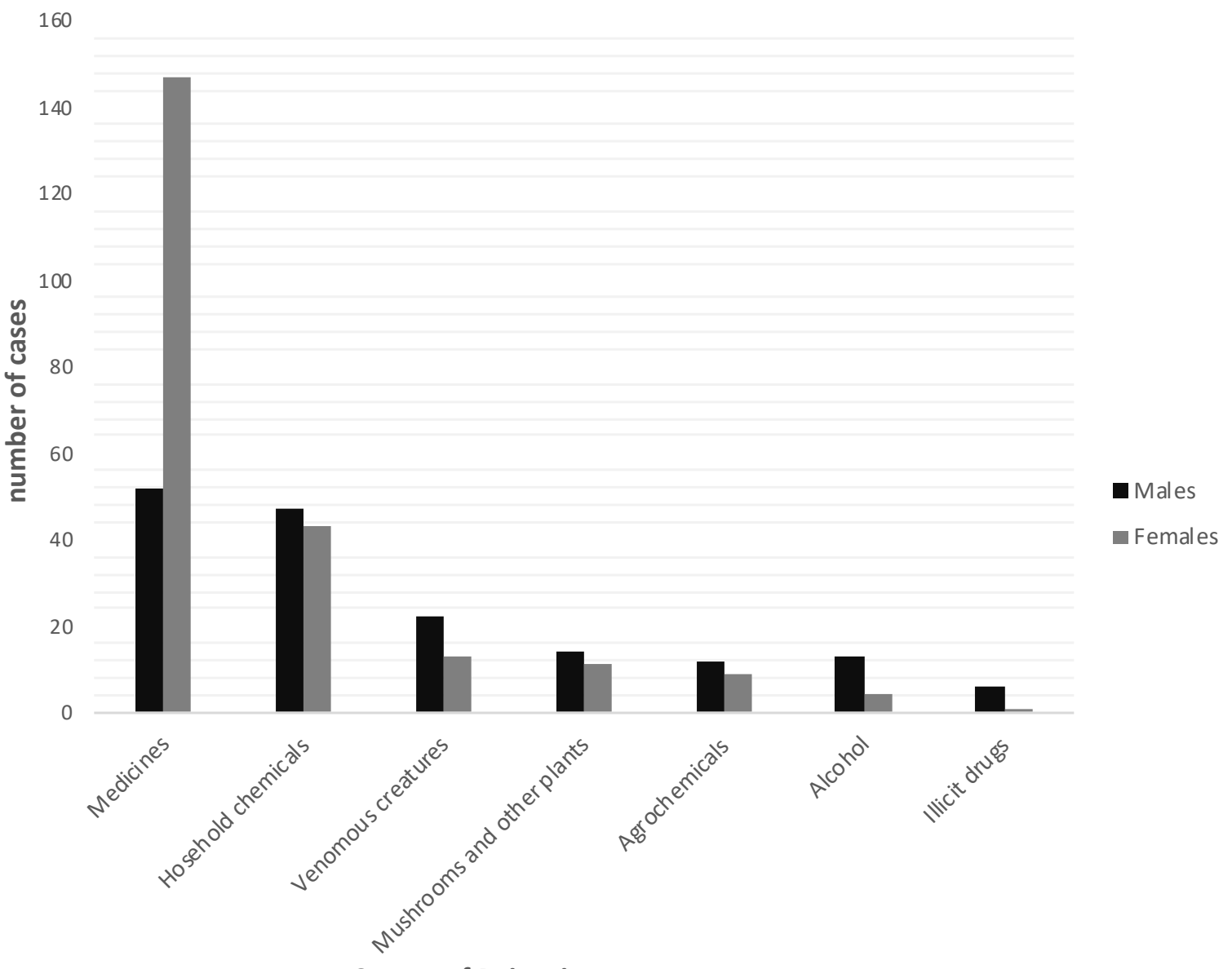

Source of Poisoning

Table A1 in the Appendix shows those aged $20-30$ years were the most affected by illicit drugs $(71 \%)$, alcohol $(65 \%)$ and medicines $(53 \%)$. Children under five years were poisoned by household chemicals $(53 \%)$, heavy metals $(32 \%)$, wild mushrooms and other plants $(32 \%)$. Agrochemicals poisoning cases were highest among those aged $20-30$ years (43\%) followed by the $0-4$ years age group (19\%).

Non-prescription medicines including traditional medicines were used most in poisoning cases (64\%), with the top three medicine groups including analgesics (47\%), antibiotics (15\%), and antiretrovirals (ARVs) (10\%). Specific medicines mostly ingested included paracetamol (30\%), ARVs (12\%), ibuprofen $(11 \%)$ and metronidazole $(7 \%)$. Only one case of opioid drugs (codeine) was recorded.

The most common sources of poisoning among females were analgesics with 66 cases out of a total of $81(82 \%)$ admittance followed by antibiotics with 24 cases out of $26(92 \%)$. Of the 17 cases poisoned by ARVs, $13(76.5 \%)$ were females. The situation was different with traditional medicines and cough mixtures, where males constituted two thirds of the cases (Figure 2). 


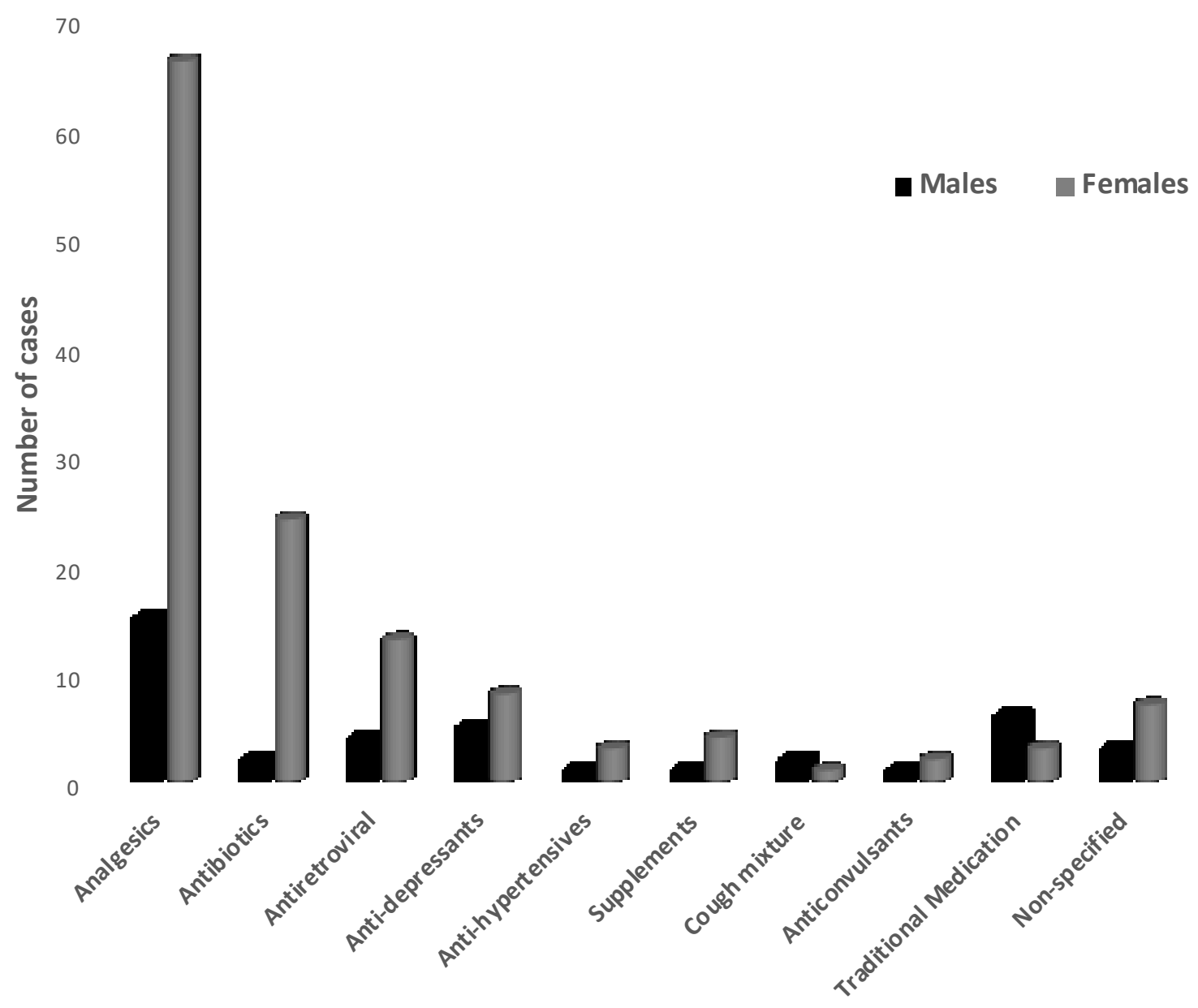

NB: \% refers to the division within medicine type between males and females

Table A2 of Appendix shows that out of the 81 total cases poisoned by analgesics, 44(54\%) were from the age group 20-30 years followed 19 (24\%) from the age group 13-19 years. Additionally, more than two thirds of the 26 cases of antibiotic poisoning and almost half of the 17 cases poisoned by ARVs were from the age group 20-30 years. The age group 5-12 years and 51 years and above had the least number of poisonings from medicines.

Amongst all the sources of poisoning, only medicines were associated significantly with females (gender), who were more likely to be poisoned by medicines compared to males (AOR $3.77,95 \% \mathrm{Cl}$ : $1.50-9.46)$.

\subsection{Sources of household chemical poisoning by age}

Paraffin $(35 \%)$ and laundry detergents $(13 \%)$ were the most ingested household chemicals. Children under 5 were typically poisoned by paraffin $(81 \%)$, laundry detergents $(64 \%)$ and turpentine $(50 \%)$ compared to all other age groups.

\subsection{Illicit drugs and alcohol poisoning by gender and age}

Poisoning by illicit drugs $(n=7)$ was mainly from marijuana $(75 \%)$, with cocaine and unspecified substances comprising the remainder split between the two. All the marijuana cases were male and the one cocaine case was female. Most (50\%) were aged between 20 to 30 and $18 \%$ between 31 to 40 years. 
Whisky, tequila, beer, wine and some unspecified alcoholic beverages were responsible for alcohol poisonings in the age group 20 to 30 years $(64 \%)$, with males (86\%) the vast majority. One under-five child was admitted for accidentally ingesting whisky.

\subsection{Poisoning by venomous creatures}

Venomous creatures identified for poisoning included snakes (56\%), scorpions (36\%) and unspecified creatures $(8 \%)$. The majority of snake and scorpion bites were experienced by males $(55 \%)$ aged 20 to 30 years $(30 \%)$.

\subsection{Factors which influenced intentional poisoning by gender}

Out of the 408 records of poisoning reviewed, reasons for intentional poisoning were recorded in 125 cases $(31 \%)$. The main reasons for intentional poisoning were relationship problems $(74 \%)$ followed by social distress $(16 \%)$, abuse $(4 \%)$ and depression $(2.4 \%)$. As previously stated, patients selfharming due to hanging or lacerations were excluded. Death of a loved one, anger, and economic problems accounted for the remainder. All the reasons were high for females except for anger which was reported by males.

\subsection{Outcomes of poisoning}

Six patients died from poisoning giving a mortality rate of $1.5 \%$. Half the deaths (3) were from ingestion of household chemicals namely white vinegar, methylated spirit and battery acid. One death from acute chemical pneumonitis as a result of ingesting white vinegar occurred in a one-year male infant who was admitted to the intensive care unit (ICU) and intubated. An overdose from traditional medicines resulted in the death of one male in the age-group 13-19 years, who was referred from a clinic to PMH. Two females died in the age groups 20-30 years and 40-49 years from illicit drugs (cocaine overdose) and methylated spirit respectively. A male patient died from ingestion of battery acid in the age-group 20-30 years. One death in the age group 30-40 years occurred from unspecified alcohol intoxication. No death was recorded in the age group 51 years and above.

Three injuries (predominantly oesophageal) were recorded from ingestion of bleach, battery acid and 'handy andy' in combination with HARPIC (ammoniated kitchen and bathroom cleaning chemicals). All of the injuries were among females.

\section{Discussion}

This study describes acute poisonings at a tertiary hospital in Gaborone, Botswana. The nature (intentional and unintentional poisoning) and sources of poisoning are described among different age groups and gender. Intentional poisoning was highest among females in the reproductive age. Most of our patients were poisoned by medicines followed by household chemicals. Failing relationships were the main reason for intentional poisoning. Six patients died from poisoning representing a $1.5 \%$ mortality rate. Whilst the mortality rate is low, our findings suggest the need for in-depth and urgent investigation regarding intentional poisoning among young women across countries including subSaharan African countries. This is because poisoning has become an increasing issue worldwide. Whilst mortality was higher among men in our study, in line with previous studies $(39,40)$, our numbers are too small to make any meaningful comparisons. It is however worth noting that our findings are similar to those of Kasule and colleagues (2009) (33).

The majority of patients in our study admitted with acute poisoning were intentional and mostly young women of reproductive age (15-45 years). This age group was nine times more likely to poison themselves compared to all others, with females four and half times more likely to intentionally poison themselves compared to males. Earlier studies in Botswana have shown an equal proportion of males and females admitted for acute poisoning (35) with the majority of admissions being unintentional (33). Consequently, we believe our findings point to an appreciable shift from previous investigations which tended to neglect intentional poisoning (self-harm) and were more focused on accidental poisoning particularly among children and older adults (41).

Accidental poisoning was high in children under 13 years. Children under five in particular recorded the highest number of accidental poisonings, similar to other studies $(40,42)$. Whilst admissions for the elderly were very low in our study, the nature of poisoning was accidental. This is similar to published studies where accidental poisonings are typically reported among children and the elderly 
$(15,43,44)$. We are not sure of the reasons behind the low rates in the elderly in our study and will be investigating this further in future studies.

Previous studies have shown that household chemicals, medicines and pesticides are the most frequent etiologic factors underlying hospitalizations due to acute poisoning $(2,7,8,23,33,35,38$, $40,44)$. Even though the order of poisoning sources in our study differ from some previous studies undertaken in Botswana $(35,38)$, the sources have largely remained the same. Malangu and others (2014) highlighted common toxic agents to be household products $(46.1 \%)$, agrochemicals $(18.8 \%)$, pharmaceuticals (14.0\%), animal and insect bites (13.0\%) (38). However, our study identified medicines as the leading poisoning sources similar to others $(26,33)$. Karadaş et al. (2011) also found that three quarters of intentional poisonings were caused by medicines, with analgesics, multiple medicines and psychiatric medicines being the principal causes (26). Earlier studies have also shown that medicines were responsible for between $87.5 \%$ to $96 \%$ of acute poisoning as part of suicide attempts, particularly among females $(23,45)$. McClure and colleagues $(2011)$ found that poisonings were greatest among young black women, with analgesic and psychiatric medicines the most commonly implicated (25). Our study is also similar to that of Rodriguez et al. (2017) in that the nature of poisoning for most patients was intentional and that younger patients between 15 and 40 years were most commonly affected (27).

Over the counter medications (paracetamol and ibuprofen) were mostly overdosed versus prescription medicines, enhanced by their availability. The availability of painkillers is also enhanced by their frequent prescribing during patients' visit to health facilities in Botswana. We will be addressing this further in future research as well as the use of antibiotics as a common mode of poisoning in our study given concerns with the current misuse of antibiotics in Botswana and increasing resistance rates $(46,47)$.

Paraffin was the greatest factor leading to hospitalizations among those aged 0 to 4 years, similar to other studies in LMICs (48). Since children have a cognitive, psychological and psycho motor immaturity, young children are at high risk for home accidents of all kinds enhanced by exploring their world through the senses (48). Since their senses of smell and taste are still relatively undifferentiated, they are more likely to mistake paraffin for clear liquids like water and drink it. Negligence on the part of parents also increases the risk of children under five getting poisoned as seen by the case of a toddler being poisoned by whisky in our study. A number of strategies have been suggested and implemented in LMICs to reduce paraffin poisoning, and we will be reviewing these with Ministry of Health personnel (49-51).

SDG 3 includes targets for reducing substance abuse, including the harmful use of alcohol (target 3.5) (52). Poisoning by illicit drugs was mainly from marijuana, cocaine and unspecified illicit substances. All marijuana cases were reported in male patients and the cocaine case was a youthful female in the 20 to 30 years age group. Alcohol poisoning affected the same age group and mainly male patients.

Our findings on hospital admissions due to self-poisoning, particularly among young women, are similar to those of other researchers $(20,22-24,38)$. Hospitalizations due to intentionally self-inflicted poisonings were prominent among women aged 15 to 24 in studies among reproductive-aged women in the USA $(20,25)$. Similar to these findings, our study showed an increasing trend of self-inflicted poisoning in those aged between 13 and 30 years in recent years. These similarities on increasing female admissions have also been observed in more recent studies in Botswana and other regions of the world including Iran and the USA $(12,25,27)$. Globally, suicide has been ranked the number one cause of mortality in young girls between 15 and 19 years (53). Further, it has been consistently found that whilst women make more suicide attempts than men, men are more likely to die in their attempts than women (54).

Few studies to date have focused on the reasons for attempting suicide. In our study, relationship problems followed by social distress, abuse, and depression, were the principal reasons for self-harm with most intentional poisoning occurring in the age-group 20 to 30 years. Whilst abuse was among the reasons for intentional poisoning, the records did not specify whether the abuse was physical, emotional or sexual. Past studies have however, reported physical, sexual and emotional abuse as factors influencing suicide $(55,56)$. More than half of the female patients poisoned themselves intentionally due to relationship problems compared to males. This was attributed to failure of love affairs, depression, economic instability, break-up of the family support system and urbanization. 
Farzaneh et al (2010) also found that romantic disappointment was a key reason for intentional poisoning among principally female students admitted to hospital in Iran (23), Other studies have also shown the prevalence of acute poisoning among the young $(38,44,57)$. Urban-based patients had the most cases of intentional poisoning in our study, which could be due to lifestyle social pressures compared with rural residents. In addition, potentially reduced family support if parents continue to live in more rural areas.

We will be investigating a number of key identified aspects in future studies in Botswana as there has for instance been limited policy interest in prioritizing female suicidal behaviour especially in LMICs; however, this is beginning to change $(52,54,55)$. This lack of interest has been exacerbated by some researchers reporting that suicidal behaviour in women can be viewed as manipulative and nonserious and that women's suicidal behaviour is inept or incompetent, although this ignores key cultural issues (56-58). Consequently, there is need for further in-depth research exploring the complex relationships between gender and intentional poisoning. Such studies would help inform future public health interventions in Botswana and wider.

\section{Study limitations}

We were aware of a number of limitations with our study. Firstly, secondary data was used to retrieve information posing challenges in terms of accuracy and completeness. However, we sought to address this by asking hospital personnel where we could for additional data. We also only undertook the study in one hospital. However, this is a leading hospital in Botswana seeing such patients. We were also unable to fully document length of hospital stay and time of exposure to admission. A number of records were excluded due to missing data. In addition, we did not record where patients reside. Finally, we were unable to provide further information on the heavy metals involved or the type of abuse unlike other studies as these were typically not recorded in patients' records $(58,59)$. Despite these limitations, we believe our findings are robust in view of our methodology and the number of patients included, and acts as a basis for discussing the implications with Ministry of Health and Wellness personnel in Botswana. Further research and activities are planned to address areas of concern.

\section{Conclusions}

Most of the intentional poisoning cases admitted to this leading hospital in Botswana occurred in the 15 to 45 year age group and among females. In general, females were more likely to be poisoned by medicines than males, with the most common poisoning source among females being analgesics while in males these were traditional medicines.

Future strategies to reduce poisoning events include instigating stricter regulations around the prescribing and dispensing of medicines, improved labelling, and safely storing common household items including paraffin, detergents, insecticides, kitchen and bathroom cleaners. There is also a need to further study handling practices and knowledge regarding pesticides as most of the poisonings by insecticides were accidental. We also believe the government in Botswana should instigate community awareness campaigns about poisons in general as well as pilot help lines and other approaches targeting the young especially young females. Subsequently, assess the outcome of such schemes in terms of reducing poisoning events versus their costs. This will enable the government in its resource considerations knowing for instance that until recently nearly $50 \%$ of women aged between 30-34 years in Botswana had HIV, and there are increasing concerns with rising antimicrobial resistance rates as well as rising rates of cardiovascular diseases in Botswana. We will be following up these suggestions and their influence to provide future direction not only to the Ministry of Health in Botswana but also wider among other sub-Saharan African countries.

\section{Acknowledgements:}

We thank the Ministry of Health and Wellness and the Princess Marina Hospital staff for availing the patient records for the accomplishment of this study.

\section{Conflicts of Interest and Sources of Funding:}

This research was funded by the University of Botswana through the internal grant system. The funder had no role in the study design, collection, analysis and interpretation of the data; writing the 
report or the decision to submit the manuscript for publication. The views expressed in this paper are those of the authors and do not necessarily reflect the views of the funding body.

All authors have no conflicts of interest to declare.

\section{References}

1. Saoraya J, Inboriboon PC. Acute poisoning surveillance in Thailand: the current state of affairs and a vision for the future. ISRN Emergency Medicine. 2013;2013.

2. Tagwireyi D, Chingombe P, Khoza S, Maredza M. Pattern and Epidemiology of Poisoning in the East African Region: A Literature Review. Journal of Toxicology. 2016;2016:26.

3. Reed RP, Conradie FM. The epidemiology and clinical features of paraffin (kerosene) poisoning in rural African children. Annals of tropical paediatrics. 1997;17(1):49-55.

4. United Nations. Economic and Social Council. Progress towards the Sustainable Development Goals - Report of the Secretary-General. 2017. Available at URL: https://unstats.un.org/sdgs/files/report/2017/secretary-general-sdg-report-2017--EN.pdf. 5. United Nations. Progress towards the Sustainable Development Goals. 2017. Available at URL: https://www.un.org/ga/search/view_doc.asp?symbol=E/2017/66\&Lang=E.

6. World Health Organization. Guidelines for poison control. 1997. Available at URL: https://www.who.int/ipcs/publications/training_poisons/guidelines_poison_control/en/.

7. Alinejad S, Zamani N, Abdollahi M, Mehrpour O. A Narrative Review of Acute Adult Poisoning in Iran. Iranian journal of medical sciences. 2017;42(4):327-46.

8. Mehrpour O, Akbari A, Jahani F, Amirabadizadeh A, Allahyari E, Mansouri B, et al. Epidemiological and clinical profiles of acute poisoning in patients admitted to the intensive care unit in eastern Iran (2010 to 2017). BMC emergency medicine. 2018;18(1):30-.

9. Wong A, Vohra R, Ruha A-M, Koutsogiannis Z, Graeme K, Dargan PI, et al. The Global Educational Toxicology Uniting Project (GETUP): an Analysis of the First Year of a Novel Toxicology Education Project. J Med Toxicol. 2015;11(3):295-300.

10. Prajapati T, Prajapati K, Tandon R, Merchant SJAPJoMT. Acute chemical and pharmaceutical poisoning cases treated in civil hospital, Ahmedabad: one year study. 2013;2(2):63-7. 11. Dorado Pombo S, Martin Fernandez J, Sabugal Rodelgo G, Caballero Valles PJ. [Epidemiology of acute poisoning: study of 613 cases in the Community of Madrid in 1994]. Revista clinica espanola. 1996;196(3):150-6.

12. Ahmadi A, Pakravan N, Ghazizadeh Z. Pattern of acute food, drug, and chemical poisoning in Sari City, Northern Iran. Human \& experimental toxicology. 2010;29(9):731-8.

13. Reichert C, Reichert P, Monnet-Tschudi F, Kupferschmidt H, Ceschi A, Rauber-Luthy C. Seizures after single-agent overdose with pharmaceutical drugs: analysis of cases reported to a poison center. Clinical toxicology. 2014;52(6):629-34.

14. Jeyaratnam J. Acute pesticide poisoning: a major global health problem. World health statistics quarterly Rapport trimestriel de statistiques sanitaires mondiales. 1990;43(3):139-44.

15. Gauvin F, Bailey B, Bratton SL. Hospitalizations for pediatric intoxication in Washington State, 1987-1997. Archives of pediatrics \& adolescent medicine. 2001;155(10):1105-10.

16. Athappan G, Balaji MV, Navaneethan U, Thirumalikolundusubramanian P. Acute renal failure in snake envenomation: a large prospective study. Saudi journal of kidney diseases and transplantation. 2008;19(3):404-10.

17. Malangu N. Acute poisoning at two hospitals in Kampala-Uganda. Journal of forensic and legal medicine. 2008;15(8):489-92.

18. Kulkarni ML, Anees S. Snake venom poisoning: experience with 633 cases. Indian pediatrics. 1994;31(10):1239-43.

19. Kanchan T, Menezes RG. Suicidal poisoning in Southern India: gender differences. Journal of forensic and legal medicine. 2008;15(1):7-14.

20. Cox S, Kuo C, Jamieson DJ, Kourtis AP, McPheeters ML, Meikle SF, et al. Poisoning hospitalisations among reproductive-aged women in the USA, 1998-2006. Injury prevention.

2011;17(5):332-7.

21. Moghadamnia AA, Abdollahi M. An epidemiological study of poisoning in northern Islamic Republic of Iran. East Mediterr Health J. 2002;8(1):88-94.

22. Islambulchilar M, Islambulchilar Z, Kargar-Maher MH. Acute adult poisoning cases admitted to a university hospital in Tabriz, Iran. Human \& experimental toxicology. 2009;28(4):185-90.

23. Farzaneh E, Mehrpour O, Alfred S, Moghaddam HH, Behnoush B, Seghatoleslam T. Selfpoisoning suicide attempts among students in Tehran, Iran. Psychiatria Danubina. 2010;22(1):34-8. 
24. Masoumi G, Ganjei Z, Teymoori E, Sabzghabaee AM, Yaraghi A, Akabri M, et al. Evaluating the Prevalence of Intentional and Unintentional Poisoning in Vulnerable Patients Admitted to a Referral Hospital. Journal of Isfahan Medical School. 2013;31:1452-60 (Persian).

25. McClure CK, Katz KD, Patrick TE, Kelsey SF, Weiss HB. The epidemiology of acute poisonings in women of reproductive age and during pregnancy, California, 2000-2004. Matern Child Health J. 2011;15(7):964-73.

26. Karadas S, Guler A, Aydin I. A retrospective analysis of acute poisoning during pregnancy. Journal of the Turkish German Gynecological Association. 2011;12(4):199-203.

27. Rodriguez A, Shibata J, Pon P, Ciroe E, Cox M. A Retrospective Review: Acute Poisonings Presenting to the Accident and Emergency Department in Botswana. SM Emerg Med Crit Care. 2017; 1(3): 1011

28. Statistics Botswana. Sustainable Development Goals - BOTSWANA DOMESTICATED

SUSTAINABLE DEVELOPMENT GOALS INDICATORS Stats Brief. 2018. Available at URL:

http://www.statsbots.org.bw/sites/default/files/special_documents/Botswana Domesticated

Sustainable Development Goals Indicators Baseline Stats Brief_0.pdf.

29. Paulozzi LJ, Xi YJP, safety d. Recent changes in drug poisoning mortality in the United States by urban-rural status and by drug type. 2008;17(10):997-1005.

30. Hoskin AF. Trends in unintentional-injury deaths during the 20th century. Statistical bulletin (Metropolitan Life Insurance Company : 1984). 2000;81(2):18-26.

31. Sustainable Development Goals Knowledge Platform. Botswana. Voluntary National Review 2017. Available at URL:

https://sustainabledevelopment.un.org/index.php?page=view\&type $=30022 \& n r=487 \&$ menu $=3170$

32. World Health Organisation. World health statistics 2016: Monitoring health for the SDGs sustainable development goals. Available at URL:

https://www.who.int/gho/publications/world_health_statistics/2016/EN_WHS2016_TOC.pdf?ua=1.

33. Kasule M, Malangu N. Profile of acute poisoning in three health districts of Botswana. African Journal of Primary Health Care \& Family Medicine. 2009;1(1):010.

34. Chandra A, Mullan P, Ho-Foster A, Langeveldt A, Caruso N, Motsumi J, Kestler A.

Epidemiology of patients presenting to the emergency centre of Princess Marina Hospital in

Gaborone, Botswana. African Journal of Emergency Medicine. 2014; 4 (3): 109-114.

35. Malangu N. Characteristics of acute poisoning at two referral hospitals in Francistown and Gaborone. South African Family Practice. 2008; 50 (3): 67-67c.

36. Malangu N. Acute Poisoning in Three African Countries: Botswana, South Africa and Uganda: University of Limpopo. 2011. Available at URL:

http://ulspace.ul.ac.za/bitstream/handle/10386/674/NMalanguDSc_Thesis_2012_May.pdf;sequence= 1.

37. Statistics Botswana. Population \& Housing Census 2011: National Statistical Tables. 2015.

Available at URL:

http://www.statsbots.org.bw/sites/default/files/publications/national_statisticsreport.pdf.

38. Malangu N. Contribution of plants and traditional medicines to the disparities and similarities in acute poisoning incidents in Botswana, South Africa and Uganda. African journal of traditional, complementary, and alternative medicines. 2014;11(2):425-38.

39. Global Health Estimates 2015. Deaths by Cause, Age, Sex, by Country and by Region, 20002015. Geneva, Switzerland: World Health Organisation; 2016.

40. Z'Gambo J, Siulapwa Y, Michelo C. Pattern of acute poisoning at two urban referral hospitals in Lusaka, Zambia. BMC emergency medicine. 2016;16:2-

41. World Health Organisation. SDG Health and Health-Related Targets. 2016. In: Monitoring Health For the SDGs [Internet]. Geneva Switzerland: WHO,. Available from:

https://www.who.int/gho/publications/world_health_statistics/2016/EN_WHS2016_Chapter6.pdf.

42. Seif E, Gomaa R, Eisa M. A Retrospective Study of Acute Poisoning in Children under 5 Years Old Admitted to Alexandria Poison Center in Egypt. World Journal of Preventive Medicine. 2016;4(2):32-9.

43. Khudair IF, Jassim Z, Hanssens Y, Alsaad WA. Characteristics and determinants of adult patients with acute poisoning attending the accident and emergency department of a teaching hospital in Qatar. Human \& experimental toxicology. 2013;32(9):921-9.

44. Azab SM, Hirshon JM, Hayes BD, El-Setouhy M, Smith GS, Sakr ML, et al. Epidemiology of acute poisoning in children presenting to the poisoning treatment center at Ain Shams University in Cairo, Egypt, 2009-2013. Clinical toxicology. 2016;54(1):20-6.

45. Dorado SP, Martín JF, Sabugal GR, Caballero PVJRce. Epidemiology of acute poisoning: study of 613 cases in the community of Madrid in 1994. 1996;196(3):150-6. 
46. Mashalla Y, Setlhare V, Massele A, Sepako E, Tiroyakgosi C, Kgatlwane J, et al. Assessment of prescribing practices at the primary healthcare facilities in Botswana with an emphasis on antibiotics: Findings and implications. International journal of clinical practice. 2017;71(12).

47. Tiroyakgosi C, Matome M, Summers E, Mashalla Y, Paramadhas BA, Souda S, et al. Ongoing initiatives to improve the use of antibiotics in Botswana: University of Botswana symposium meeting report. Expert review of anti-infective therapy. 2018;16(5):381-4.

48. Tshiamo WJljonp. Paraffin (kerosene) ${ }^{*}$ poisoning in under-five children: A problem of developing countries. 2009;15(3):140-4.

49. Schwebel DC, Swart D. Preventing paraffin-related injury. Journal of injury \& violence research. 2009;1(1):3-5.

50. Lang T, Thuo N, Akech S. Accidental paraffin poisoning in Kenyan children. Trop Med Int Health. 2008;13(6):845-7.

51. Nixon J, Spinks A, Turner C, McClure R. Community based programs to prevent poisoning in children 0-15 years. Injury prevention : journal of the International Society for Child and Adolescent Injury Prevention. 2004;10(1):43-6.

52. World Health Organization. World health statistics 2016: monitoring health for the SDGs sustainable development goals: World Health Organization; 2016.

53. Ajdacic-Gross V, Weiss MG, Ring M, Hepp U, Bopp M, Gutzwiller F, et al. Methods of suicide: international suicide patterns derived from the WHO mortality database. Bulletin of the World Health Organization. 2008;86:726-32.

54. Vijayakumar L. Suicide in women. Indian journal of psychiatry. 2015;57(Suppl 2):S233.

55. Cooperman NA, Simoni JM. Suicidal ideation and attempted suicide among women living with HIVIAIDS. Journal of behavioral medicine. 2005;28(2):149-56.

56. Seedat S, Stein MB, Forde DR. Association between physical partner violence, posttraumatic stress, childhood trauma, and suicide attempts in a community sample of women. Violence and victims. 2005;20(1):87-98.

57. Ram P, Kanchan T, Unnikrishnan B. Pattern of acute poisonings in children below 15 years--a study from Mangalore, South India. Journal of forensic and legal medicine. 2014;25:26-9.

58. Nakhaee S, Amirabadizadeh A, Nakhaee S, Zardast M, Schimmel J, Ahmadian-Moghadam J, et al. Blood lead level risk factors and reference value derivation in a cross-sectional study of potentially lead-exposed workers in Iran. BMJ open. 2019;9(7):e023867-e.

59. Bohn DK. Lifetime physical and sexual abuse, substance abuse, depression, and suicide attempts among Native American women. Issues in Mental Health Nursing. 2003;24(3):333-52. 


\section{Supplement}

Table A1: Sources of poisoning by age category

\begin{tabular}{|c|c|c|c|c|c|c|c|c|c|}
\hline \multirow{2}{*}{$\begin{array}{l}\text { Source of } \\
\text { poisoning }\end{array}$} & \multicolumn{8}{|c|}{ Age in Years n(\%) } & \multirow[b]{2}{*}{$\begin{array}{l}>60 \\
(\mathrm{~N}=6)\end{array}$} \\
\hline & $\begin{array}{l}\text { Total } \\
\mathrm{n}(\%)\end{array}$ & $\begin{array}{l}0-4 \\
(\mathrm{~N}=81)\end{array}$ & $\begin{array}{l}5-12 \\
(\mathrm{~N}=21)\end{array}$ & $\begin{array}{l}13-19 \\
(\mathrm{~N}=53)\end{array}$ & $\begin{array}{l}20-30 \\
(\mathrm{~N}=166)\end{array}$ & $\begin{array}{l}31-40 \\
(\mathrm{~N}=50)\end{array}$ & $\begin{array}{l}41-50 \\
(\mathrm{~N}=20)\end{array}$ & $\begin{array}{l}51-60 \\
(\mathrm{~N}=4)\end{array}$ & \\
\hline Medicines & $200(49.0)$ & $16(8.0)$ & $3(1.5)$ & $39(19.5)$ & $105(52.5)$ & $26(13.0)$ & $8(4.0)$ & $1(0.5)$ & $2(1)$ \\
\hline $\begin{array}{l}\text { Household } \\
\text { Chemicals }\end{array}$ & $90(22.1)$ & $48(53.3)$ & $5(5.6)$ & $4(4.4)$ & $23(25.6)$ & $7(7.8)$ & $1(1.1)$ & $1(1.1)$ & $1(1.1)$ \\
\hline $\begin{array}{l}\text { Venomous } \\
\text { Creatures }\end{array}$ & $35(8.6)$ & $2(5.7)$ & $5(14.3)$ & $4(11.4)$ & 11(31.4) & $6(17.1)$ & $4(11.4)$ & 0 & $3(8.6)$ \\
\hline $\begin{array}{l}\text { Mushrooms and } \\
\text { other plants }\end{array}$ & $25(6.1)$ & $8(32.0)$ & $7(28.0)$ & $1(4.0)$ & $2(8.0)$ & $3(12.0)$ & $4(16)$ & 0 & 0 \\
\hline Agrochemicals & $21(5.1)$ & $4(19)$ & 0 & $2(9.5)$ & $9(42.9)$ & $3(14.3)$ & $3(14.3)$ & 0 & 0 \\
\hline Alcohol & $17(4.2)$ & $1(5.9)$ & 0 & $2(11.8)$ & $11(64.7)$ & $2(11.8)$ & 0 & $1(5.9)$ & 0 \\
\hline Illicit drugs & $7(1.7)$ & 0 & 0 & 0 & $5(71.4)$ & $2(28.6)$ & 0 & 0 & 0 \\
\hline Heavy metals & $6(1.5)$ & $2(33.3)$ & $1(16.7)$ & $1(16.7)$ & 0 & $1(16.7)$ & 0 & $1(16.7)$ & 0 \\
\hline
\end{tabular}

Table A2: Medicine Type by Age Group ( $n=172$ )

\begin{tabular}{|c|c|c|c|c|c|c|c|c|c|}
\hline \multirow[b]{2}{*}{$\begin{array}{l}\text { Pharmaceutical } \\
\text { Type }\end{array}$} & \multicolumn{7}{|c|}{ Age in Years n (\%) } & \multirow[b]{2}{*}{$\begin{array}{l}51-60 \\
(n=1)\end{array}$} & \multirow[b]{2}{*}{$\begin{array}{l}>60 \\
(n=2)\end{array}$} \\
\hline & $\begin{array}{l}\text { Total } \\
\text { N (\%) }\end{array}$ & $\begin{array}{l}0-4 \\
(n=15)\end{array}$ & $\begin{array}{l}5-12 \\
(n=3)\end{array}$ & $\begin{array}{l}13-19 \\
(n=33)\end{array}$ & $\begin{array}{l}20-30 \\
(n=88)\end{array}$ & $\begin{array}{l}31-40 \\
(n=21)\end{array}$ & $\begin{array}{l}41-50 \\
(n=8)\end{array}$ & & \\
\hline Analgesics & $81(47.4)$ & $5(6.2)$ & $2(2.5)$ & $19(23.5)$ & $44(54.3)$ & $9(11.1)$ & $2(2.5)$ & 0 & 0 \\
\hline Antibiotics & $26(15.2)$ & $3(11.5)$ & 0 & $3(11.5)$ & $18(69.2)$ & $1(3.8)$ & 0 & 0 & $1(3.8)$ \\
\hline Antiretroviral & $17(9.9)$ & 0 & 0 & $4(23.5)$ & $8(47.1)$ & $5(29.4)$ & 0 & 0 & 0 \\
\hline Anti-depressants & $13(7.6)$ & 0 & 0 & $3(23.1)$ & $7(53.8)$ & $1(7.7)$ & $2(15.4)$ & 0 & 0 \\
\hline Hypertensive & $4(2.3)$ & $2(50.0)$ & 0 & 0 & 0 & $2(50.0)$ & 0 & 0 & 0 \\
\hline Supplements & $5(2.9)$ & 0 & 0 & $1(20.0)$ & $4(80.0)$ & 0 & 0 & 0 & 0 \\
\hline Cough mixture & $3(1.8)$ & $1(33.3)$ & 0 & 0 & $1(33.3)$ & 0 & $1(33.3)$ & 0 & 0 \\
\hline Anticonvulsants & $3(1.8)$ & 0 & 0 & 0 & $1(33.3)$ & $1(33.3)$ & $1(33.3)$ & 0 & 0 \\
\hline $\begin{array}{l}\text { Traditional } \\
\text { Medicine }\end{array}$ & $9(5.3)$ & $3(33.3)$ & $1(11.1)$ & $2(22.2)$ & $1(11.1)$ & 0 & $2(22.2)$ & 0 & 0 \\
\hline Other & $10(5.8)$ & $1(10.0)$ & 0 & $1(10.0)$ & $4(40.0)$ & $2(20.0)$ & 0 & $1(10.0)$ & $1(10.0)$ \\
\hline
\end{tabular}

